\title{
我国湿地生态系统恢复与保护技术探究
}

\author{
刘红萍 \\ 云南省林业调查规划院生态分院
}

DOI:10.32629/eep.v3i3.709

[摘 要] 湿地的生态价值、经济价值和社会价值是很高, 作为水体系统和陆地系统相互影响而产生的生态系统, 也是人类社会最佳的生存环 境,同时也聚集了大量的、多种类的生物。湿地和人类的发展是息息相关的,湿地为人类社会的发展提供了大量的资源, 同时又具有很高的生 态环境保护效益,在美化环境、调节气候、降解污染物等方面发挥着无可替代的作用。在当前生态环境保护理念盛行的今天,湿地作为地球 之肺, 将更加受到社会各界的高度重视。本文中着重研究湿地的生态系统恢复和保护技术,希望能提升湿地建设水平,充分地发挥湿地的作用 价值。

[关键词]湿地; 生态系统; 恢复; 保护; 技术研究

当前, 从世界范围来看, 湿地已经占到了陆地面积的 $6 \%$ 。但是也要看到, 面积众多的湿地得到了破坏了, 被用于住宅用地、工业用地等。这就造成 的湿地面积和湿地质量都出现了下降。湿地的生态价值和生态效益主要体 现在以下方面。湿地作为对区域生态多样性维护的重要举措, 也是保持生 物多样性的最有效的方式。天然性的湿地, 将为各种鸟类和鱼类提供良好 的生存条件。湿地作为重要的生物遗产基因库, 将有效地减少人类生产生 活活动对野生动植物的干扰。同时, 湿地在水利工作中发挥着调蓄洪水的 作用, 将最大限度将减少洪水和旱灾对人类经济发展造成的损失。湿地中 的水蒸发将会引发降水, 有助于调节区域气候。加强湿地生态系统的恢复 和保护技术显得更为重要。

\section{1 湿地系统的生态恢复和保护举措}

1.1 水质的保护研究

结合湿地的实际情况来制定完善、高效的水污染源控制体系, 完善湿 地水资源的管理制度。对于湿地中的垃圾实施规划地收集, 集中力量对湿 地中倾倒垃圾的情况进行严厉打击。科学地管理湿地, 分析湿地的具体类 型和主要污染物来源, 科学化地对湿度实施管理和保护, 湿地一般具有河 流和湖泊符合特征。同时, 湿地系统有关的水域禁止传输危险化学品的船 舶通行, 采取各种举措切实确保湿地中的水环境安全。

\section{2 水系的保护研究}

为了对湿地的生态系统进行更好地保护, 对湿地的水系保护要做到更 加规范, 特别是避免湿地周边环境对水洗造成破坏。湿地管理区域的政府
要强化工作力度, 对生态水位实施科学化的调度, 这样推动湿地系统中的 各类植物能够得到正常生长。

1.3 栖息地的保护研究

湿地生态系统恢复和保护工作中, 首先要对湿地中的动植物分布情 况、生长栖息环境了解清楚, 这样才能为湿地生态系统的保护提供必要的 数据支持。在动植物相对集中的区域, 要尽可能地减少人为活动的影响, 确保湿地中的动植物能够安静地生活成长。特别是鸟类的栖息地, 必要的 时候要建设防护围栏, 鼓励农民退耕还湿。

\section{2 湿地生态系统的恢复和保护举措研究}

2.1 基质恢复措施

湿地生态系统的恢复举措比较多, 但是最为关键的是基质的恢复。但 是具体的恢复方法是比较多, 通常有对湿地底泥的污染物进行清除, 塑 造地形以及保护表土等方法。这里面, 塑造地形指的是应用挖低填高或 者削高填低的方式对因为地势起伏所造成的低地沉淀区域实施治理, 让 这一区域变成具有独特造型的湿度生态环境。表土的保护指的是在施工 开始之前, 要将基质条件比较好的湿度表土进行剥离, 将其搬离到土壤 条件比较差的区域, 等到施工结束后, 再将原先的湿度表土运回到原位, 这样确保更大范围的湿地具有良好的质量。回填覆盖处理方式指的是对 于那些基地条件比较差的区域, 以种植带方式或者分层方式来将不同厚 度的基质进行回填, 这样促使动植物更好地多样化生长, 对基质理化特 征实施有效改善。
术实施前 $\mathrm{NO}_{x}$ 排放量为 $801 \mathrm{mg} / \mathrm{m}^{3}$ 。为此, 按照在线全程监测结果, 通常为 $360 \mathrm{mg} / \mathrm{m}^{3}$, 只有在极少数煅烧异常工况情况下偶尔会达到 $400 \mathrm{mg} / \mathrm{m}^{3}$ 以上。故, 结合各方面监测数据来看, 不仅满足相关管理部门制定的环保规范标准, 脱氮效果还十分明显。

由上述内容可以看出, 脱氮技术能够在此水泥工业生产线上成功使 用。从行业角度来看, 不仅达到了预期的技术经济指标, 还为行业范围起到 了良好的示范作用 ${ }^{[3]}$ 。生产建设者应结合自身情况、资金储备以及排污需 求等因素进行可信性分析, 这样一来, 水泥工业化生产建设才能朝着更为 科学合理的方向发展, 进而推动现代化经济建设的全面发展进程。

\section{4 结束语}

综上所述, 脱氮技术在新型干法水泥生产线上的运用, 不仅能够满足 相关管理部门制定的规范标准, 脱氮效果还十分明显, 还能够做到绿色环 保, 节能减排。如, 脱氮管阀门开度为 $10 \%$ 、窑产量为 $5600 \mathrm{t} / \mathrm{d}$ 、吨熟料氨水 消耗为 $1.29 \mathrm{~kg}$ 、氨水喷入量为 $300 \mathrm{~kg} / \mathrm{h}$ 废气总管排放量在 $340 \mathrm{mg} / \mathrm{m}^{3}$ 。当氨
水价格在 1200 元 $/ \mathrm{t}$ 计, 吨熟料增加成本为 1.55 元, 综合考虑生产线排污费 用的下降与政府相关资金补助, 增加成本均在可接受范围。事实证明, 只有 在水泥工业生产过程, 运用科学技术才能使脱氮效果达到预期, 进而促进 行业的快速稳定发展。故, 相关人员应将上述分析内容与科研结果, 更多地 用于不同生产建设要求和废气排放需求的水泥工业企业, 以使其服务于现 代化经济建设的全面发展进程, 为创建绿色工厂、节能减排创造更好的经 济和社会效益。

\section{[参考文献]}

[1]林岗,张彦隆,曹文志.同步脱氮除磷技术研究进展[J].工业水处 理,2019,39(10):7-13.

[2]李柏林,任晓玲,李毕. 溶解氧对单级颗粒污泥自养脱氮系统影响的 模拟[J].中国环境科学,2019,39(12):5126-5133.

[3]朱英豪.活性污泥法处理垃圾渗滤液新型脱氮技术探讨[ J].资源节 约与环保,2019,(09):99. 


\section{2 岸坡恢復措施}

岸坡恢复指的是对于湿地中水陆交接的区域的植被分层来水质情况 恢复岸坡, 具体可以使用生态砖、植物护坡、石块护坡等多种方式。生态 砖护坡模式对易于水流冲击坞塌的岸坡区域利用生态砖来恢复。生态砖的 多孔性和高强度, 将很好地阻挡水流的冲蚀。同时, 生态砖的缝隙处将容易 成长出一种生长迅速的植物, 这样就能提升岸坡的稳定性。植被护坡的方 式指的是利用发达根系的植物对于土壤侵蚀的岸坡区域, 以植物根系的快 速成长来将湿地岸坡的稳定性提升上去。块石护坡方式通常是利用石笼来 护坡, 这对于提升岸坡的稳定性具有巨大的作用。根据水流的冲刷力在岸 坡区域放置相应的石块, 将大石块铺设在临水区域的上层, 将小的碎石铺 设在下面, 同时在其上方将适量的种植土覆盖。这样就能制止水流对岸坡 的侵蚀, 同时有助于岸坡植物的恢复。从而杜绝出现各种地质滑坡或者塌 陷, 从而提升湿地斜坡的稳定性。

\section{3湿地生态修复工程}

有些湿地已经生态功能衰退, 需要进行生态系统的恢复。一般地, 对于 生态功能退化的湿地要使用植被恢复、截断污染源以及生态补水等方式实 施综合化的治理。湿地附近的居民生活用水排放、工业污水的排放以及农 业养殖废水的排放, 都有可能造成湿地水质的污染, 容易造成湿地生态系 统功能的受损。为了提升湿地生态系统的功能, 一般要采取生态补水、动 植物保护等举措, 从而提升流入湿地的水环境质量, 这样来对湿地的生态 系统进行恢复和保护。

2. 4 强化湿地保护的法制化建设力度

强化湿地的法制化建设力度, 将提升对污染环境和破坏湿地行为的约 束力。当前, 从国家层面出台了湿地保护的法律法规。但是湿地保护的法 制化保护工作还存在一些问题。第一, 明确性、具有可操作性的保护条款 缺乏, 保护条款的内容显得十分单一, 不具有系统性, 往往是对湿地生态系 统中的单一元素进行保护。湿地系统保护的法律政策的完整性和系统性是 缺乏的。要知道, 我国湿地种类是多种多样的, 有的湿地具有多种类型湿地 特征。所以当前的湿地保护法律法规的针对性不强、准确性不足和可操作 性弱化, 都影响到当前湿地生态系统的保护工作成效。因此, 需要立法部门 可以出台专门性的适度保护行政法规条例, 将湿地作为单一化的生态系统
实施整体化的保护, 对湿地生态保护行为进行规范, 及时遏制湿地面积大 量下降的趋势。

2. 5 强化湿地保护的宣传教育工作

在湿地生态系统恢复和保护工作, 不仅需要政府部门科学化的治理和 依法管理, 更需要全体人民的积极参与。公民湿地保护意识和能力将对提 升湿地生态系统的恢复和保护工作发挥着十分关键的作用。所以, 要积极 加强湿地生态系统保护的教育宣传工作, 让公众对湿地生态系统的价值作 用要充分地了解, 在全社会对湿地生态系统的破坏行为坚决禁止, 全社会 形成积极保护湿地生态系统的良好氛围。湿地公园内建设专题保护的宣传 教育栏, 组建湿地生态系统保护志愿者团队, 向更多的人来宣传湿地保护 知识。

\section{3 结语}

当前很多湿地面临着湿地面积缩减和湿地生态功能弱化的现实困境, 造成这一现状的原因就是湿地周边居民的生活、生产污染废弃物的排放, 对湿地生态系统的价值作用认识不够, 在湿地管理模式上滞后等多重原因 所造成的。对于湿地生态系统保护工作中出现这些情况, 目前可以采取一 些举措来进行补救。第一, 对湿地实施科学化的管理, 以控制污染物排放、 规范农民的家畜养殖行为等方式减少对湿地生态系统造成的负面影响。第 二, 积极实施生态修复工作。以生态补水的方式对受到损害的湿地生态系 统实施修复。第三, 加大对湿地生态系统保护法规的建设力度, 严厉打击各 种破坏湿地生态系统的行为。第四, 加大对湿度生态系统保护的宣传教育 工作。提升民众对湿地生态系统价值作用的认识, 积极参与湿地生态系统 保护工作, 构筑湿地生态系统保护的强大力量。

\section{[参考文献]}

[1]汤国平,刘小青.湿地功能及保护措施探讨[J].黄河水利职业技术 学院学报,2001(2):4-6.

[2]赵建成, 吴跃峰, 李盼威, 温带暖温带交接带生物多样性研究: 木兰围 场自然保护区科学考察集[M].北京:科学出版社,2005.

[3]王京国,白山,王毅杰.湿地的功能与湿地资源的保护对策 [J]. 吉林 林业科技,2010(2):54-56. 